\title{
A relação entre o plano de ensino e a prática docente em uma disciplina específica de história e filosofia da ciência em um curso de licenciatura em química
}

Patricia Vecchio Guarnieri patyvecchio@gmail.com

0000-0002-4443-6792

Universidade Estadual Paulista "Júlio de Mesquita Filho", Bauru, São Paulo

Sandra Regina Teodoro Gatti sandragatti@gmail.com 0000-0001-5791-2498

Universidade Estadual Paulista "Júlio de Mesquita Filho", Bauru, São Paulo

\section{RESUMO}

Neste artigo, buscamos responder os seguintes questionamentos: De que forma o docente responsável por uma disciplina de História e Filosofia da Ciência e Ensino de Ciências se apropria das orientações fornecidas pelo seu plano de ensino, o qual é disponibilizado pela universidade? Sua formação acadêmica influencia nesse processo? Os resultados de pesquisas estão presentes no plano de ensino? E na fala do professor? Nossa amostra contempla um curso de Licenciatura em Química de uma universidade pública do Estado de São Paulo. Para tanto, analisamos o plano de ensino de uma disciplina específica sobre História e Filosofia da Ciência, assim como a entrevista realizada com o professor responsável por ela. Os resultados evidenciaram certa divergência entre as orientações do documento e a prática do docente. Dessa forma, os resultados sugerem a necessidade de repensarmos a articulação entre os documentos que organizam os cursos e a prática dos professores que irão efetuá-los.
\end{abstract}

PALAVRAS-CHAVE: História e filosofia da ciência. Plano de ensino. Formação de professores. 


\section{INTRODUÇÃO}

Esta pesquisa surge em decorrência da relevância da articulação entre a História e Filosofia da Ciência (HFC) e o ensino que vem sendo destacada em várias pesquisas (MATTHEWS, 1995; BASTOS, 1998; TEODORO, 2000; GATTI, 2005; MARTINS, 2007; PORTO, 2010; MARTORANO, 2012; GATTI; NARDI, 2013; NORONHA, 2014; STANZANI; GUARNIERI; BASTOS, 2015; CAMPOS, 2016; GATTI; NARDI, 2016; MORAIS, 2016).

Nesse sentido, Lombardi (1997) aponta a existência de um consenso quase unânime no que tange a importância da HFC na formação científica, em que autores defendem as potencialidades advindas da utilização de tal abordagem (GIL-PÉREZ, 1993; MATTHEWS, 1995; PORTO, 2010; HÖTTECKE; SILVA, 2011; QUEIRÓS, 2012).

Entretanto, há uma escassez de trabalhos que discutem essa temática tendo como foco a formação inicial dos professores de Química, conforme evidenciado em um levantamento bibliográfico realizado por Guarnieri e Gatti (2017) o qual analisou o foco dos trabalhos das três últimas edições (2011, 2013 e 2015) do Encontro Nacional de Pesquisa em Educação em Ciências (ENPEC) que se referem à temática da HFC no Ensino de Química.

Os resultados apontaram que o maior foco dos trabalhos está centrado em "[...] estudos teóricos sobre algum tema ou conceito específico da área de Química que esteja interligado a HFC" (GUARNIERI; GATTI, 2017, p. 8). As autoras evidenciaram que há um número considerável de trabalhos que apresentam desenvolvimento de propostas didáticas, contudo são poucos os trabalhos que estão voltados para a Formação Inicial, sendo o cerne das pesquisas a Educação Básica.

Diante de tais evidências, Guarnieri e Gatti (2017) defendem que:

\footnotetext{
Essa falta de trabalhos reflete na formação do futuro professor, uma vez que este não vivencia o planejamento, ou até mesmo o desenvolvimento, de uma proposta que articule a HFC ao Ensino de Química, não apresentará esses aspectos em sua prática, pois pela falta de conhecimento específico se limitará a utilizar tal abordagem (GUARNIERI; GATTI, 2017, p. 6).
}

Sendo assim, corroborando com tal ideia, Peduzzi, Martins e Ferreira (2012) defendem que inserir a HFC na Formação Inicial pode possibilitar que os licenciados problematizem seus modelos didáticos, podendo adquirir uma concepção de ciência mais crítica e fundamentada, podendo contribuir para a compreensão da Ciência de forma humana, levando em conta todos os contextos que influenciaram na sua construção, a fim de desmistificar visões ingênuas de Ciência, que muitas vezes contribuem para a desmotivação dos estudantes em relação a se apropriarem do conhecimento científico.

Diante de tais reflexões e preocupações com a articulação da HFC e o ensino, compreendemos que uma das lacunas que dificulta esse processo advém da Formação Inicial, sendo assim surgem nossos questionamentos para esta pesquisa: De que forma o docente responsável por uma disciplina de História e Filosofia da Ciência e Ensino de Ciências se apropria das orientações fornecidas pelo seu plano de ensino, o qual é disponibilizado pela universidade? Sua 
formação acadêmica influencia nesse processo? Os resultados de pesquisas estão presentes no plano de ensino? E na fala do professor?

\section{FUNDAMENTAÇÃO TEÓRICA}

Como já apontado anteriormente, discussões sobre a importância da HFC no ensino têm feito parte das preocupações de vários pesquisadores, tanto em âmbito nacional quanto internacional. Delizoicov, Slongo e Hoffmann (2011) afirmam que:

\footnotetext{
[...] pesquisadores brasileiros e estrangeiros que têm se dedicado a investigar o ensino de Biologia, Física e Química, são unânimes em anunciar que a inserção do debate epistemológico, via História e Filosofia da Ciência, nos espaços de formação docente, devidamente articulado às suas práticas de ensino, é estratégia profícua para uma melhor preparação dos professores e à superação do ensino dogmático e memorístico que ainda perdura na Educação Científica, em diversos âmbitos (p. 8841).
}

Corroborando com tal afirmação, têm sido apontadas por pesquisadores potencialidades proporcionadas pelo uso da abordagem de HFC (MATTHEWS, 1995; BASTOS, 1998; TEODORO, 2000; GATTI, 2005; MARTINS, 2007; PORTO, 2010; MARTORANO, 2012; STANZANI; GUARNIERI; BASTOS, 2015; CAMPOS, 2016). Dentre elas, temos: a humanização das ciências; rompimento de visões dogmáticas sobre a Ciência; desenvolvimento do pensamento crítico; melhor compreensão dos conteúdos científicos; compreensão das dificuldades dos estudantes por parte dos professores; melhor formação do professor; presença de discussões sobre o papel da mulher na Ciência; dentre outros aspectos.

Matthews (1995) resume bem essas ideias ao discorrer sobre o fato de que a inserção da HFC no ensino poderia:

\footnotetext{
[...] humanizar as ciências e aproximá-las dos interesses pessoais, éticos, culturais e políticos da comunidade; podem tomar as aulas de ciências mais desafiadoras e reflexivas, permitindo, deste modo, o desenvolvimento do pensamento crítico; podem contribuir para um entendimento mais integral de matéria científica, isto é, podem contribuir para a superação do "mar de falta de significação" que se diz ter inundado as salas de aula de ciências, onde fórmulas e equações são recitadas sem que muitos cheguem a saber o que significam; podem melhorar a formação do professor auxiliando o desenvolvimento de uma epistemologia da ciência mais rica e mais autêntica, ou seja, de uma maior compreensão da estrutura das ciências bem como do espaço que ocupam no sistema intelectual das coisas (MATTHEWS, 1995, p. 165).
}

No entanto, há discussões também sobre as dificuldades e os limites que envolvem a utilização da HFC. Podemos destacar, por exemplo, a falta de conhecimento específico dos professores sobre a HFC (HÖTTECKE; SILVA, 2011); o desconhecimento de fontes, materiais e estratégias envolvendo a HFC (PORTO, 2010); visões distorcidas sobre a Natureza da Ciência (GIL, PÉREZ, 1993); a postura passiva dos estudantes em sala de aula (CAMPOS, 2016); o preconceito dos estudantes quanto à utilização de uma abordagem histórico-filosófica, pois eles têm uma visão de que estão desperdiçando tempo, não enxergando a HFC como sendo importante para a compreensão do conceito científico (GATTI; NARDI; SILVA, 2010); as questões burocráticas como a falta de tempo e de 
profissionais com formação específica em HFC para atuarem nos cursos de licenciatura (FERREIRA; FERREIRA, 2010); entre outras.

A fim de buscar minimizar tais dificuldades e auxiliar na utilização da HFC que contemple as potencialidades destacadas, algumas perspectivas e abordagens devem ser utilizadas.

Primeiramente, assumimos a posição de que tais aspectos devem estar de acordo com a Nova Historiografia da Ciência. Trata-se de uma tendência atual da historiografia defendida por Alfonso-Goldfarb, Ferraz e Beltran (2004), a qual implica em "[...] um processo de análise não continuísta, portanto, sem ler o passado a partir do presente; mas também evitando a imposição generalizada de fórmulas descontinuístas" (ALFONSO-GOLDFARB; FERRAZ; BELTRAN, 2004, p. 55).

Porto (2010) defende essa tendência evidenciando que ela está voltada para uma análise pontual e detalhada de estudos de caso, buscando a especificidade dos episódios que influenciaram a construção da Ciência. Para isso, é necessário buscar os significados de tais episódios de acordo com o pensamento da época, sendo possível assim identificar as continuidades e rupturas desse processo de construção "[...] bem como as particularidades das interpretações das várias fontes que contribuíram para o desenvolvimento de uma determinada obra científica" (PORTO, 2010, p.165).

Tal tendência implica na utilização de uma visão Diacrônica da Ciência, a qual orienta que sejam considerados os contextos sócio-histórico-cultural em que ocorreu algum episódio que contribuiu para o processo de construção do conhecimento científico. No entanto, para que não haja distorções da Ciência, e seja possível uma compreensão adequada desse processo é preciso que sejam feitas comparações com as teorias do mesmo período, apropriando-se das ideias aceitas para determinada época, contexto e cultura (FORATO; PIETROCOLA; MARTINS, 2011).

A literatura apresenta dois tipos de abordagens teóricas, são elas: a abordagem internalista e a externalista. Beltran, Saito e Trindade (2014) as definem como:

A corrente internalista pressupõe que a ciência seja autônoma, neutra e tenha uma dinâmica própria, independente da sociedade que a gerou. Desse modo, deve ser estudada em função dos seus próprios objetos. Já a perspectiva, a externalista, analisa a ciência como uma atividade humana que, para ser compreendida, precisa ser estudada no conjunto social, político e econômico da época (BELTRAN; SAITO; TRINDADE, 2014, p. 37).

Defendemos a posição de que deve existir um equilíbrio entre ambas as abordagens, pois "uma análise histórica completa implica recorrer tanto às considerações científicas, como também a fatores extra científicos" (OLIVEIRA; SILVA, 2012, p. 45).

As abordagens e visões aqui discutidas devem ser contempladas em um ensino que integre a História e a Filosofia. Tal articulação muitas vezes não aparece nos currículos dos cursos de Licenciatura em Química, o que se pode notar é um isolamento de disciplinas que consideram apenas a Filosofia ou a História da Ciência/Química. Conquanto, em nosso entendimento, não há como dissociá-las, havendo a necessidade de serem abordadas de forma interligada. 
Levando em conta as discussões apresentadas aqui, analisamos como tem sido a relação entre a prática docente e as orientações advindas do plano de ensino, em uma disciplina de História e Filosofia da Ciência e Ensino de Ciências em um curso de Licenciatura em Química.

\section{METODOLOGIA}

O trabalho em questão faz parte de uma pesquisa de mestrado cujo objetivo foi compreender qual o perfil formativo relacionado à HFC fornecido por cursos de Licenciatura em Química de uma universidade pública do Estado de São Paulo. Dessa forma, os dados aqui apresentados foram extraídos de tal pesquisa, porém o objetivo para este artigo é responder as seguintes questões: De que forma o docente responsável por uma disciplina de História e Filosofia da Ciência e Ensino de Ciências se apropria das orientações fornecidas pelo seu plano de ensino, o qual é disponibilizado pela universidade? Sua formação acadêmica influencia nesse processo? Os resultados de pesquisas estão presentes no plano de ensino? E na fala do professor?

À vista disso, analisamos o plano de ensino de uma disciplina intitulada 'História e Filosofia da Ciência e Ensino de Ciências' de um curso de Licenciatura em Química de uma universidade pública do Estado de São Paulo, assim como a entrevista realizada com o professor responsável por tal disciplina no ano de 2017.

A pesquisa aqui realizada é de caráter qualitativo, em que:

O objetivo da pesquisa está então, menos em testar aquilo que já é bem conhecido (por exemplo, teorias já formuladas antecipadamente) e mais em descobrir o novo e desenvolver teorias empiricamente fundamentadas. Além disso, a validade do estudo é avaliada com referência ao objeto que está sendo estudado, sem guiar-se exclusivamente por critérios científicos teóricos, como no caso da pesquisa quantitativa. Em vez disso, os critérios centrais da pesquisa qualitativa consistem mais em determinar se as descobertas estão embasadas no material empírico, ou se os métodos foram adequadamente selecionados e aplicados, assim como na relevância das descobertas e na reflexividade dos procedimentos (FLICK, 2009, p.24).

A entrevista feita com o docente é caracterizada como sendo uma entrevista semiestruturada, a qual "[...] se desenrola a partir de um esquema básico, porém não aplicado rigidamente, permitindo que o entrevistador faça as necessárias adaptações" (LÜDKE; ANDRÉ, 2012, p. 34).

A fim de analisar os dados, nos pautamos na metodologia da Análise de Conteúdo (BARDIN, 2016). Esse método é definido como:

Um conjunto de instrumentos metodológicos cada vez mais sutis em constante aperfeiçoamento, que se aplicam a "discursos" (conteúdos e continentes) extremamente diversificados. $O$ fator comum dessas técnicas múltiplas e multiplicadas - desde o cálculo de frequências que fornece dados cifrados, até a extração de estruturas traduzíveis em modelos - é uma hermenêutica controlada, baseada na dedução: a inferência. Enquanto esforço de interpretação, a análise de conteúdo oscila entre os dois polos do rigor da objetividade e da fecundidade da subjetividade (BARDIN, 2016, p. 15) 
Inicialmente, foi realizada uma leitura flutuante tanto do plano de ensino quanto da entrevista, a fim de identificar os pontos em comum, e possibilitar uma análise comparativa.

Em seguida, analisamos os seguintes tópicos do plano de ensino: objetivos; conteúdo programático; metodologia; e, critérios de avaliação e aprendizagem. 0 intuito foi de identificar como tal documento se apropria dos resultados de pesquisa, evidenciando os aspectos relacionados à visão de Ciência que pretende abordar e os assuntos que buscam discutir, fazendo uma articulação com o que defendemos na fundamentação teórica.

Posteriormente, fizemos uma análise do currículo Lattes do docente, a fim de extrair algumas informações sobre sua formação, as quais foram confrontadas com a entrevista.

Após isso, foi realizada a leitura de forma aprofundada da entrevista, buscando identificar os trechos que se assemelham aos tópicos do plano de ensino. Com base em tais trechos, evidenciamos a apropriação do docente no que tange as questões advindas da literatura e também de que forma ele contempla as orientações apresentadas no plano de ensino.

Por fim, comparamos os trechos do plano de ensino com a fala do docente, com a intenção de compreender como sua formação acadêmica influenciou nas escolhas que fez para a disciplina.

A seguir apresentamos o contexto da pesquisa, a fim de situar o leitor sobre as características do curso que foi analisado, principalmente, no que se refere à disciplina de História e Filosofia da Ciência e Ensino de Ciências e ao docente responsável por ela.

\section{o Contexto da Pesquisa}

O Curso em questão faz parte de um dos quatro campus que oferecem a Licenciatura em Química, de uma universidade pública do Estado de São Paulo.

Sua fundação neste campus se deu em 2001, começando suas atividades apenas em 2002. O objetivo de sua criação foi suprir a carência de professores de Química e Ciências legalmente habilitados nessa região e as deficiências na formação dos professores de Química e Ciências, habilitados e não habilitados em exercício. ${ }^{1}$

Em 2011 ocorreu a reestruturação do curso, levando a implantação da modalidade Bacharelado em Química Ambiental e Tecnológica.

Hoje, o curso de Química dessa universidade possui núcleo comum² para as modalidades de Licenciatura e Bacharelado, tendo como finalidade principal a formação de profissionais aptos para atuarem no mercado de trabalho, participando ativa e criticamente do desenvolvimento da sociedade. Também busca suprir a lacuna de professores na área específica, que estejam comprometidos com o desenvolvimento social, justo e democrático. Além de procurar promover reflexões a respeito dos processos de construção do conhecimento. ${ }^{1}$ semestres, sendo estruturado por disciplinas de caráter Específico, Didático- 

Optativas.

Dentre as disciplinas oferecidas pelo Curso, apenas uma se refere especificamente a História e Filosofia da Ciência e Ensino de Ciências.

Esta disciplina é identificada como sendo de caráter específico, estando localizada no primeiro semestre do curso. É ofertada como núcleo comum para as modalidades de Licenciatura e Bacharelado em Química, com carga horária de sessenta horas, duração de um semestre.

Sua descrição é fornecida pela ementa, a qual evidencia que:

A disciplina de HFC enfoca as diferentes perspectivas epistemológicas com ênfase no trabalho científico, domínio e aplicação da metodologia de ensino e didática própria do ensino de ciências, e transposição didática dos conteúdos de modo a promover nos alunos as competências e habilidades próprias para o ensino de Ciências e Química. ${ }^{1}$

Diante dessa contextualização a respeito do curso e da disciplina que iremos analisar, e a fim de responder uma das nossas questões de pesquisa, se faz necessária a descrição de quem é o professor que ministra a disciplina. Porém, é indispensável à apresentação de algumas informações para a compreensão do contexto em que se encontra esse docente. Essas informações foram retiradas da entrevista realizada com ele.

Após a reestruturação do Curso, buscando contemplar as exigências advindas dos documentos governamentais (Parecer do Conselho Nacional de Educação e Deliberações do Conselho Estadual de Educação), algumas disciplinas foram reelaboradas, realocadas, inseridas e até extintas. Em decorrência disso, a disciplina de História e Filosofia da Ciência e Ensino de Ciências, a qual era ofertada no terceiro semestre, passou a ser ministrada no primeiro semestre.

Dessa forma, a fim de oportunizar que todos os estudantes cursassem essa disciplina, foram necessárias algumas mudanças de horários. Sendo assim, os professores que tinham afinidade com a temática da HFC ficaram responsáveis por outras disciplinas, havendo choque de horários.

Devido a isso, o professor que ficou responsável por ela foi o docente que assumia o cargo de coordenador do curso. A seguir apresentamos o Quadro 1, que traz alguns dados a respeito desse docente.

Quadro 1 - Descrição da formação do docente responsável pela disciplina com base em seu currículo Lattes

\begin{tabular}{|c|l|}
\hline Formação Inicial & $\begin{array}{l}\text { Bacharel em Química - 2003 } \\
\text { Licenciatura em Química - 2008 }\end{array}$ \\
\hline Mestrado & Fez o doutorado direto \\
\hline Doutorado & Doutorado em Química Inorgânica - 2009 \\
\hline \multirow{2}{*}{ Áreas de atuação } & $\begin{array}{l}\text { Ciências Exatas e da Terra; Química Inorgânica; Físico- } \\
\text { Química; Ciências Humanas; Ensino-Aprendizagem; Avaliação } \\
\text { da Aprendizagem; Métodos e Técnicas de Ensino; Material } \\
\text { Didático. }\end{array}$ \\
\hline
\end{tabular}

(Fonte: as autoras)

Com base na entrevista realizada aprofundamos as informações presentes no currículo Lattes no que diz respeito a sua formação. 
À vista disso, tem-se que o docente atua, desde 2010, em cursos de graduação, ministrando principalmente disciplinas de Química Inorgânica, Química Geral, Estágio Supervisionado, entre outras. Porém, nunca lecionou na Educação Básica.

Há quatro anos atua como docente neste curso e em 2017 foi o primeiro ano que ministrou a disciplina de História e Filosofia da Ciência e Ensino de Ciências.

O docente não fez nenhuma especialização na área do Ensino, tendo apenas cursado a Licenciatura em Química em 2008.

No que se refere ao contato do docente com discussões histórico-filosóficas, durante sua graduação em Bacharelado em Química, cursou apenas uma disciplina que era focada em aspectos específicos da História da Química, não havendo articulações com a Filosofia e nem com o ensino. No entanto, durante a entrevista menciona que esse contato com a História da Química não influencia em sua prática, pois foi algo pontual, conteudista e que viu há muito tempo.

A seguir apresentaremos a análise e discussão dos dados do plano de ensino e da entrevista realizada com o docente responsável pela disciplina.

\section{ANÁLISE E DISCUSSÃO DOS DADOS}

O plano de ensino é organizado em seções, sendo elas: objetivos; conteúdo programático; metodologia; bibliografia básica e complementar; critérios de avaliação e aprendizagem; regime de recuperação e ementa. Dentre essas, iremos analisar apenas as que estão em negrito, devido à estrutura da entrevista. Seguiremos a ordem que tais tópicos aparecem no plano de ensino para a realização das análises tanto do referido documento, quanto da entrevista. Vale lembrar que o plano de ensino não foi elaborado pelo professor que assumiu a disciplina, sendo este formulado e disponibilizado pela universidade.

\section{Objetivos}

O plano de ensino indica objetivos gerais e específicos que se espera proporcionar ao final do curso. Dessa forma, o Quadro 2 apresenta os trechos desse documento no que se refere aos objetivos, assim como uma síntese das principais ideias que emergem dos trechos, a fim de facilitar a compreensão do leitor.

Quadro 2 - Objetivos gerais e específicos retirados do plano de ensino da disciplina

\begin{tabular}{|c|c|c|}
\hline \multicolumn{3}{|c|}{ Objetivos de acordo com o plano de ensino } \\
\hline Página & Trecho do plano de ensino & Síntese ${ }^{3}$ \\
\hline 33 & $\begin{array}{l}\text { Realizar uma }(1)^{4} \text { abordagem crítica } \\
\text { sobre o desenvolvimento do } \\
\text { conhecimento científico, (2) tendo em } \\
\text { vista uma perspectiva que avalie sua } \\
\text { formação histórica, suas determinações } \\
\text { culturais, suas limitações e contradições } \\
\text { como resposta aos problemas humanos, } \\
\text { (3) além de suas implicações no processo } \\
\text { de ensino e aprendizagem. }\end{array}$ & $\begin{array}{l}\text { 1. Abordagem crítica sobre o } \\
\text { desenvolvimento da Ciência; } \\
\text { 2. Avaliar a formação histórica do } \\
\text { conhecimento científico, } \\
\text { evidenciando os contextos } \\
\text { envolvidos; } \\
\text { 3. Implicações da HFC no processo } \\
\text { de ensino e aprendizagem. }\end{array}$ \\
\hline 33 & (1) Refletir sobre o processo histórico de & 1 e 2. Refletir sobre o processo de \\
\hline
\end{tabular}




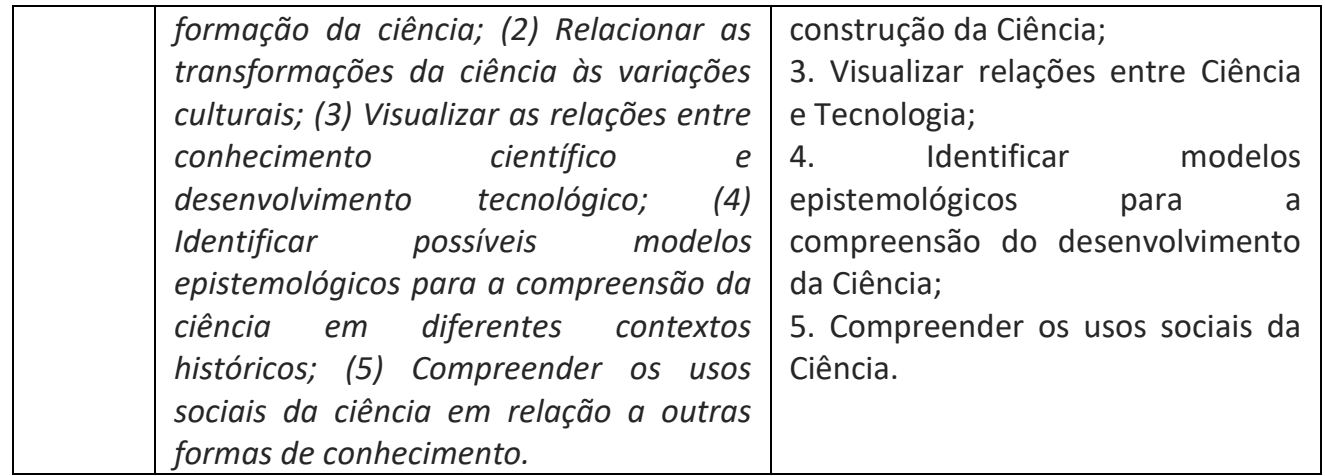

(Fonte: as autoras)

Identificamos aqui que o foco da disciplina é desenvolver uma visão mais adequada sobre a Ciência, a fim de compreender os impasses que envolveram sua construção no decorrer dos anos. Buscando também trabalhar com aspectos relacionados à Filosofia no que se refere à compreensão da Ciência, além de realizar discussões a respeito das implicações sobre a HFC no processo de ensino e aprendizagem.

Referente aos objetivos, o plano de ensino está alinhado com o que vem sendo proposto nos resultados de pesquisa, no que tange as temáticas a serem trabalhadas nas disciplinas de HFC (TEODORO, 2000; GATTI, 2005; CAMPOS, 2016). Tais pesquisas sugerem uma discussão sobre aspectos históricos, filosóficos, possibilitando sua articulação, indo ao encontro do que é discutido a respeito da necessidade de abordar esses aspectos como sendo complementares, e não enxergando-os de forma a ser independentes (MARTINS, 2007).

Além desse aspecto têm-se também as discussões sobre as particularidades da Ciência, e também sua utilização no ensino, fato este apontado por autores como sendo algo fundamental quando se pretende promover uma alfabetização científica adequada, que envolva uma visão pertinente sobre a Natureza da Ciência, evidenciando que este é um processo de construção, desenvolvido por cientistas que não são "gênios" isolados, e sofrem a influência de vários contextos (social, econômico, político e cultural) (GIL-PÉREZ, 1993; MATTHEWS, 1995; BASTOS, 1998; TEODORO, 2000; GATTI, 2005; MARTINS, 2007; PORTO, 2010; QUEIRÓS, 2012; CAMPOS, 2016).

No entanto, compreendemos que a visão que o docente tem sobre a disciplina influencia muito na forma como esses tópicos serão, ou não, abordados durante as aulas. A fim de compreender quais objetivos o docente considera para essa disciplina, durante a entrevista fizemos o seguinte questionamento: "Quais são os objetivos da disciplina de História e Filosofia da Ciência?" O Quadro 3 apresenta a fala do docente em relação aos objetivos elencados por ele durante a entrevista, assim como no Quadro 2.

Quadro 3 - Fala do docente em relação a sua compreensão sobre os objetivos da disciplina

\begin{tabular}{|c|l|l|}
\hline \multicolumn{3}{|c|}{ Objetivos de acordo com a compreensão do docente } \\
\hline Linhas & \multicolumn{1}{|c|}{ Fala do docente } & \multicolumn{1}{c|}{ Síntese } \\
\hline $355-359$ & $\begin{array}{l}\text { (1) Ah...fornecer base pro, pros estudantes } \\
\text { que "tão" chegando né, é abrir um pouco } \\
\text { os olhos deles, pra eles olharem com mais } \\
\text { criticidade a...ah como que eu vou colocar, }\end{array}$ & $\begin{array}{l}\text { 1. Fornecer uma base sobre } \\
\text { aspectos da Ciência; } \\
\text { 2. Trabalhar o senso crítico em ao desenvolvimento da } \\
\text { relaço ao dental }\end{array}$ \\
\hline
\end{tabular}




\begin{tabular}{|c|c|c|}
\hline & $\begin{array}{l}\text { (2) eles serem mais críticos no...no que diz } \\
\text { respeito assim a...a como que aquele } \\
\text { conteúdo que é apresentado foi } \\
\text { desenvolvido e (3) construírem essas } \\
\text { relações entre uma disciplina e outra, e } \\
\text { também (4) a gente fala sobre método } \\
\text { científico. }\end{array}$ & $\begin{array}{l}\text { Ciência; } \\
\text { 3. Construir relações entre as } \\
\text { disciplinas; } \\
\text { 4. Discutir sobre o método } \\
\text { científico, e e conceitos } \\
\text { específicos da Ciência. }\end{array}$ \\
\hline $367-369$ & $\begin{array}{l}\text { Olha...refletir sobre, o cara tem que (1) ter } \\
\text { a capacidade de refletir sobre aquilo que } \\
\text { ele vai estudar daqui pra frente, (2) ele } \\
\text { não pode simplesmente aceitar } \\
\text { passivamente qualquer conteúdo }\end{array}$ & $\begin{array}{l}\text { 1. Capacidade de refletir sobre o } \\
\text { que vai estudar; } \\
\text { 2. Não aceitar de forma passiva } \\
\text { o conteúdo ministrado. }\end{array}$ \\
\hline
\end{tabular}

(Fonte: as autoras)

Os objetivos citados pelo docente aparecem de certa forma no plano de ensino da disciplina. Assim, com base em sua fala, o foco parece estar na compreensão do processo de construção do conhecimento científico, com o intuito de possibilitar ao licenciando o desenvolvimento do senso crítico em relação à Ciência.

Entretanto, o docente não menciona os objetivos que dizem respeito às questões epistemológicas da Ciência, às relações entre o conhecimento científico e o desenvolvimento tecnológico, às implicações nos processos de ensino e aprendizagem, dentre outros pontos.

Fazendo uma comparação entre o que é sugerido pelo plano de ensino e a compreensão do docente em relação aos objetivos da disciplina, podemos inferir que o docente compreende a necessidade de uma visão fundamentada sobre a Natureza da Ciência e o desenvolvimento do senso crítico do licenciando, porém pontos que deveriam ser essenciais na disciplina não aparecem em sua fala, como por exemplo, a articulação das discussões sobre HFC com o ensino.

Apesar de no referido documento a articulação da HFC com o ensino ser um dos tópicos a serem desenvolvidos na disciplina, ela não aparece na fala do docente, o que nos permite concluir que isso não é discutido durante as aulas.

Contudo, isso pode ser decorrente do fato de esta ser a primeira vez que o docente ministra a disciplina, sendo que ele não possui formação específica para trabalhar com tal temática. Além disso, durante a entrevista deixa claro não "[...] ser o mais qualificado, capacitado, para ministrar essa disciplina", no entanto pede contribuições dos colegas que já atuaram na mesma.

À vista disso, é que compreendemos a necessidade de uma formação específica em HFC para que os objetivos da disciplina sejam alcançados em sua magnitude, possibilitando uma formação adequada ao futuro professor sobre essa temática, podendo levá-lo a utilizar tal abordagem em suas aulas de maneira adequada (HÖTTECKE; SILVA, 2011; MARTINS; SILVA; PRESTES, 2014; CAMPOS, 2016).

\section{Conteúdo Programático}

São elencados no plano de ensino conteúdos a serem abordados durante a disciplina, com o intuito de possibilitar a efetivação dos objetivos propostos. 
Assim sendo, elaboramos o Quadro 4 que contempla os conteúdos como são recomendados pelo referido documento.

Quadro 4 - Conteúdo programático retirado do plano de ensino da disciplina

\begin{tabular}{|c|c|c|}
\hline \multicolumn{3}{|c|}{ Conteúdo programático de acordo com o plano de ensino } \\
\hline Página & Trecho do plano de ensino & Síntese \\
\hline 33 & $\begin{array}{l}\text { (1) História das ciências: moderna, } \\
\text { ciências nos séculos XIX, XX e XXI. Aspectos } \\
\text { gerais da história da ciência, } \\
\text { especialmente focalizados no âmbito da } \\
\text { astronomia, física e matemática; (2) } \\
\text { Filosofia das ciências: Bacon, Kuhn, } \\
\text { Popper, Feyerabent, Lakatos. Modelos } \\
\text { epistemológicos e seus diferentes critérios } \\
\text { de racionalidade; (3) Implicações da HFC } \\
\text { para o ensino de ciências. }\end{array}$ & $\begin{array}{l}\text { 1. História das ciências; } \\
\text { 2. Filosofia das ciências; } \\
\text { 3. Implicações da HFC para o } \\
\text { Ensino de Ciências. }\end{array}$ \\
\hline
\end{tabular}

(Fonte: as autoras)

Podemos perceber que as temáticas abordadas envolvem a Ciência de modo geral, não fazendo especificações em relação à Química, o que seria interessante se tratando de um curso de Licenciatura em Química, e pelo fato da disciplina estar alocada no primeiro semestre do curso, em que o estudante ainda não teve o contato com nenhum conteúdo específico da Química.

Um ponto que chama a atenção aqui é a presença de tópicos sobre alguns dos filósofos da Ciência e seus modelos epistemológicos. É importante que haja tais discussões, pois compreender tais modelos possibilita um melhor entendimento sobre a construção da Ciência, além de proporcionar a articulação entre a História e a Filosofia, como um dos aspectos importantes e essenciais em uma disciplina de HFC (MARTINS, 2007).

Na descrição dos conteúdos, não fica explícito qual o foco das discussões a respeito das implicações da HFC para o Ensino de Ciências, não se pode afirmar pelo plano de ensino que serão discussões sobre os limites e as potencialidades de sua utilização, ou se está se referindo às discussões sobre como utilizá-la em sala de aula, o que deve ser priorizado, entre outros aspectos. O que se espera é que haja uma articulação entre ambos os focos, tanto a discussão dos limites e das potencialidades, como da sua utilização no ensino (MATTHEWS, 1995).

Todavia, assim como evidenciado para o tópico relacionado aos objetivos, o seguimento das orientações advindas do plano de ensino depende das escolhas feitas pelo docente responsável pela disciplina.

Com intenção de verificar como o docente se apropria de tais orientações, durante a entrevista fizemos a seguinte questão: "Como você pensou a organização dessa disciplina de História e Filosofia da Ciência?".

Durante a entrevista o docente menciona ter trabalhado mais os conceitos filosóficos do que os históricos, entendendo que a História está dentro da Filosofia. À vista disso, buscamos saber quais temáticas da Filosofia ele abordou, pedindo para que ele detalhasse os assuntos que foram discutidos durante a disciplina. No Quadro 5 apresentaremos a análise das falas do docente no que diz respeito à organização da disciplina. 
Quadro 5 - Fala do docente a respeito dos conteúdos que aborda durante a disciplina

\begin{tabular}{|c|c|c|}
\hline \multicolumn{3}{|c|}{ Conteúdos trabalhados pelo docente durante a disciplina } \\
\hline Linhas & Fala do docente & Síntese \\
\hline $\begin{array}{l}426-433 \\
435-439\end{array}$ & $\begin{array}{l}\text { [...] (1) indutivismo, falsificacionismo } \\
\text { do...fugiu, enfim...fiz atividades em } \\
\text { grupo justamente pra relacionar. (2) } \\
\text { Essa atividade aí eu achei interessante, } \\
\text { é então, era pra relacionar os aspectos } \\
\text { históricos do desenvolvimento de um } \\
\text { dos temas a seguir a luz do indutivismo } \\
\text { e do falsificacionismo, e eu (3) pedi pra } \\
\text { eles fazerem um levantamento sobre o } \\
\text { desenvolvimento da teoria atômica, } \\
\text { teoria do...a descoberta do efeito } \\
\text { fotoelétrico, teoria da força vital, as } \\
\text { teorias de ligação química né, ligações } \\
\text { de valência e orbitais moleculares e o } \\
\text { comportamento dos gases, então pra } \\
\text { eles pegarem e verem como se } \\
\text { desenvolveu e como foi aperfeiçoando } \\
\text { até os modelos atuais.[...] (4) E depois } \\
\text { a estrutura das revoluções científicas, } \\
\text { ah... (5) a teoria anarquista do } \\
\text { conhecimento, (6) e novamente uma } \\
\text { atividade do mesmo tipo né, pra eles } \\
\text { explicarem usando alguns episódios } \\
\text { históricos, a teoria motora, a teoria do } \\
\text { flogisto, formato da Terra, teoria de } \\
\text { Nernest, ah...(7) e depois foi um } \\
\text { pouquinho sobre a filosofia do } \\
\text { Bachelard, e pra essa aula eu até } \\
\text { convidei um aluno do doutorado né. }\end{array}$ & $\begin{array}{l}\text { 1. Indutivismo e falsificacionismo; } \\
2 \text { e } 6 \text {. Atividades em grupo para } \\
\text { relacionar aspectos históricos de } \\
\text { um tema à luz do indutivismo e do } \\
\text { falsificacionismo; } \\
\text { 3. Levantamento sobre o } \\
\text { desenvolvimento de alguns } \\
\text { conceitos da química; } \\
\text { 4. Estrutura das revoluções } \\
\text { científicas; } \\
\text { 5. Teoria anarquista } \\
\text { conhecimento; do } \\
\text { 7. Filosofia do Bachelard, ministrada } \\
\text { por um aluno do doutorado. }\end{array}$ \\
\hline
\end{tabular}

(Fonte: as autoras)

Referente aos conteúdos a serem abordados durante a disciplina, o foco dado, diante das escolhas do docente, foi à Filosofia da Ciência. Referente à questão da História da Ciência/Química, o docente pediu para que os estudantes pesquisassem como se deu o desenvolvimento de alguns conceitos específicos, no entanto, não deixa claro como isso foi trabalhado na disciplina.

No que diz respeito ao conteúdo programático da disciplina e aos conteúdos que o docente menciona em sua fala, temos que ele não contempla em sua aula, de forma explícita, os aspectos relacionados à História da Ciência nos séculos XIX, XX e XXI e também não menciona fazer discussões sobre as implicações da HFC no ensino.

Apesar de vir especificado no plano de ensino da disciplina como um dos tópicos a ser trabalhado, a questão do ensino não é desenvolvida pelo docente. Este busca realizar discussões mais gerais sobre HFC, devido ao fato de se tratar de uma disciplina de núcleo comum para os cursos de licenciatura e bacharelado.

Além disso, outro fator que pode contribuir para suas escolhas é decorrente da sua formação, na qual não vivenciou experiências que proporcionassem tais discussões, pois como mencionou durante a entrevista teve apenas uma disciplina voltada para a História da Química, extremamente conteudista. No 
entanto, entendemos que ter o contato com tais temáticas durante a formação não garante a apropriação do docente sobre esses aspectos, entretanto refletir sobre a HFC neste momento pode possibilitar que isso ocorra (CAMPOS, 2016).

O docente responsável pela disciplina desenvolve pesquisas na área de Química Inorgânica, começando a se aproximar da área do ensino recentemente, trabalhando com questões mais práticas, como é o caso da elaboração de materiais didáticos. Dessa forma, notamos a influência que a sua formação tem em suas escolhas enquanto professor da disciplina.

Conquanto, enxerga a necessidade de mais uma disciplina com esse enfoque, no meio do curso, para tratar desses aspectos num momento em que o licenciando já teve contato com outras disciplinas, aprofundando assim tais discussões.

\section{Metodologia de ensino e Critérios de Avaliação da Aprendizagem}

O plano de ensino da disciplina orienta a utilização de algumas metodologias que o professor pode seguir, a fim de alcançar os objetivos propostos. Deste modo, o documento indica que sejam realizadas aulas expositivo-dialogadas, discussões e trabalhos em grupo, estudos dirigidos, além da elaboração de sínteses de aulas e projeções em vídeo.

Em relação a esse aspecto, perguntamos ao docente quais as estratégias e metodologias ele utiliza em suas aulas para atingir os objetivos citados durante a entrevista. Primeiramente, o docente busca justificar suas escolhas com base no que ele acredita que deve ser possibilitado ao futuro professor, que no caso se refere à autonomia dos licenciandos, pois estes estão sendo formados para atuarem como cidadãos críticos, que impõem suas opiniões e visões de mundo.

Defendendo essa postura, busca trabalhar com atividades em grupo, aulas dialogadas e, por se tratar de uma turma grande, também faz o uso de aulas expositivas.

O docente não se pauta em apenas um instrumento, diversificando suas aulas e investindo em atividades que coloquem os licenciandos para trabalhar, fazer pesquisas e socializar com a turma. Dessa forma, busca trabalhar com: discussões; debates; resenhas; trabalhos individuais e em grupo; planejamento de aulas; provas escritas; e auto avaliação.

Consideramos que estas são atividades que atendem aos objetivos de uma disciplina de HFC, pois possibilitam a interação e momentos de discussões e reflexões por parte dos futuros professores.

É importante salientar que as metodologias adotadas pelo docente, estão de acordo com o que é proposto pelo plano de ensino, permitindo a inferência de que há apropriação das orientações advindas do documento por parte do professor.

Tanto na fala do docente quanto no plano de ensino, não são dados detalhes sobre esses instrumentos, não sendo possível afirmar os reais objetivos das atividades propostas. Para isso, seria necessário o acompanhamento das aulas a fim de compreender quais os objetivos de tais instrumentos e como eles são utilizados, possibilitando assim a análise de sua relevância em relação aos 
objetivos e o que se espera de tal disciplina de acordo com os resultados de pesquisas, as quais discutem a compreensão de uma visão adequada sobre Natureza da Ciência, o desenvolvimento do pensamento crítico, melhor formação tanto do professor quanto do estudante, melhor compreensão dos conteúdos, entre outros pontos discutidos no tópico da Fundamentação Teórica (GIL-PÉREZ, 1993; MATTHEWS, 1995; BASTOS, 1998; TEODORO, 2000; GATTI, 2005; MARTINS, 2007; PORTO, 2010; MARTORANO, 2012; STANZANI; GUARNIERI; BASTOS, 2015; CAMPOS, 2016).

\section{CONSIDERAÇÕES FINAIS}

Articulações entre a HFC e o ensino tem sido foco de muitas discussões no que diz respeito a uma alfabetização científica que proporcione uma visão adequada sobre Ciência, a fim de possibilitar melhor compreensão sobre a construção do conhecimento.

No entanto a efetivação dessa articulação ainda não é algo natural. Principalmente, na Educação Básica existem muitas dificuldades a serem enfrentadas. Dessa forma, entendemos que para isso ser possível, é necessário que os professores tenham o contato com a HFC em algum momento de sua formação. À vista disso, nos posicionamos de acordo com o fato de que todo docente tenha essa experiência, de forma adequada, em sua formação inicial.

Com base nesse posicionamento, buscamos compreender como a HFC tem permeado um curso de Licenciatura em Química de uma universidade pública do Estado de São Paulo.

Para isso, buscamos responder os seguintes questionamentos: De que forma o docente responsável por uma disciplina de História e Filosofia da Ciência e Ensino de Ciências se apropria das orientações fornecidas pelo seu plano de ensino, o qual é disponibilizado pela universidade? Sua formação acadêmica influencia nesse processo? Os resultados de pesquisas estão presentes no plano de ensino? E na fala do professor?

Com o intuito de responder tais questões, investigamos o plano de ensino de uma disciplina que aborda especificamente aspectos históricos e filosóficos, a qual é intitulada como "História e Filosofia da Ciência e o Ensino de Ciências". Além disso, analisamos também a entrevista realizada com o docente responsável pela disciplina no ano de 2017.

Referente ao plano de ensino, temos que este indica em suas orientações assuntos pertinentes quando se trata da HFC. Os tópicos que compõe o documento estão bem articulados entre si, existindo coerência entre o que se espera da disciplina, e o que se propõe para que seja possível atingir as expectativas almejadas.

Os objetivos e o conteúdo programático estão em comum acordo, ambos abordam questões gerais sobre a HFC, desde a discussão de especificidades sobre a Ciência, até questões voltadas para a História da Ciência, os filósofos e a articulação entre a História e a Filosofia da Ciência. 
É importante destacar que indicam a necessidade de abordar sobre a importância da HFC nos processos de ensino e aprendizagem. Este é um fato muito positivo, pois busca promover essa articulação, que é indicada já no nome da disciplina. Referente à metodologia e os critérios de avaliação e aprendizagem, consideramos que as orientações são adequadas para o que é proposto pela disciplina.

Todavia, compreendemos que seguir tais orientações depende das escolhas e das perspectivas que o docente responsável tem sobre a temática da disciplina, sendo a sua formação uma das grandes contribuintes para os passos que o docente irá seguir.

Entendendo essa influência do professor para a real efetivação do plano de ensino, analisamos a entrevista realizada com ele, a qual teve como objetivo identificar suas concepções sobre a disciplina e como ele a organiza.

Com base nos dados advindos da entrevista, é preciso lembrar que este docente não está ministrando a disciplina por escolha sua, isso aconteceu devido à falta de profissionais com formação específica em HFC para atuar no horário que a ela foi estabelecida. Diante disso, temos aqui um professor que possui formação voltada para a área de Química Inorgânica, e que há pouco tempo começou a se envolver com discussões e projetos da área do ensino, mas que mesmo assim não tem afinidade sobre a temática da HFC.

Apesar de o docente ter pedido ajuda aos colegas de profissão, foi ele quem fez as escolhas sobre a organização da disciplina, de acordo com sua compreensão, que vai ao sentido de que os estudantes devem ter conhecimento sobre a HFC a fim de que saibam avaliar as informações que chegam até eles.

Assim sendo, optou por trabalhar com o foco voltado para questões da Filosofia da Ciência, discutindo sobre Indutivismo, Falsificacionismo, Revoluções Científicas, a teoria de Bachelard, entre outros assuntos. No que se refere ao tópico relacionado à História da Ciência, pediu para que os estudantes realizassem pesquisas sobre a temática.

O docente não faz discussões a respeito da importância da HFC para os processos de ensino e aprendizagem. Justifica isso devido ao fato de ser uma disciplina com núcleo comum para o Bacharelado e a Licenciatura. No entanto, defende a necessidade de haver de mais uma disciplina no currículo, localizada mais na metade do curso, que discuta sobre tais questões.

Notamos assim, que por mais que venha especificado esse tópico no plano de ensino, o docente não o aborda durante suas aulas. Isso também pode ser decorrente da sua formação, o qual durante a graduação teve um contato isolado com a História da Química que menciona ter sido algo "memorístico", e por ter escolhido seguir na área da Química Inorgânica em sua pós-graduação, o que lhe distancia, de certa forma, das discussões a respeito da HFC.

Dessa forma, fica evidente como a formação do professor influencia em suas escolhas, sendo assim é necessário que já na formação inicial a HFC seja algo presente e que permeie não apenas uma disciplina específica, mas que seja natural o seu processo de articulação com as demais disciplinas, pois a HFC não é 
um conteúdo a mais a ser ensinado, e sim faz parte do próprio processo de desenvolvimento da Ciência.

Para o plano de ensino é notável a apropriação dos resultados de pesquisa, pois os tópicos indicados para serem trabalhados estão coerentes com o que vem sendo defendido. Já no que se refere à prática do professor não conseguimos evidenciar tal apropriação de forma clara, o que mais uma vez possa estar relacionado à sua formação, pois ele não teve contato com tais discussões, e também por ter sido "obrigado" a ministrar uma disciplina pela qual não possui afinidade.

Desta maneira, devemos pensar em caminhos para que as orientações dos documentos sejam implantadas na prática do docente. Para isso, é necessário repensar sobre a forma como tais documentos foram escritos, se eles de fato dão suporte para os professores desenvolverem os tópicos propostos.

É preciso entender a HFC como algo que está presente em todo o desenvolvimento da Ciência, e não apenas como uma disciplina isolada. Ao reestruturar os cursos é fundamental que exista coerência entre o perfil de formando que se deseja, e as condições para alcançá-lo. Os documentos devem ser claros, e a instituição deveria se preocupar com as especificidades de cada disciplina, a fim de direcionar os professores que de fato tem afinidade com o que é proposto, disponibilizando verbas para contratações, ao invés de remanejar professores para suprir a carência de profissionais. 


\title{
The relationship between the teaching plan and the teaching practice in a specific discipline of history and philosophy of science from a chemistry degree course
}

\begin{abstract}
In this article, we seek to answer the following questions: How does the professor responsible for a discipline of History and Philosophy of Science and Science Teaching appropriate the guidelines provided by his teaching plan, which is made available by the university? Does his academic formation influence this process? Are the research results present in the teaching plan? And in the professor's speech? Our sample includes a course of teacher education programs courses in Chemistry of a public university in the State of São Paulo. We analyze the teaching plan of the discipline and the interview conducted with the professor responsible for it. The results showed a certain divergence between the orientations of the document and the practice of the teacher. Therefore, the results suggest the need to rethink the articulation between the documents that organize the courses and the practice of the professors who will perform them.
\end{abstract}

KEYWORDS: History and philosophy of science. Teaching plan. Teacher formation. 


\section{NOTAS}

1 Muitas das informações utilizadas aqui foram extraídas da homepage do curso, não iremos apresentar o link para manter o sigilo em relação à identificação do curso.

2 Possuem disciplinas comuns para ambas às modalidades, sendo que em algum momento do curso os estudantes devem optar por uma das modalidades.

3 Chamamos de síntese, pois o objetivo é resumir as ideias apresentadas no plano de ensino ou na fala do docente, a fim de facilitar a compreensão do leitor. Todos os quadros da análise seguem esse modelo.

4 Os números entre parênteses representam o contexto em que estão inseridos os tópicos que dão origem a síntese.

5 Os trechos foram retirados do plano de ensino na íntegra, estando disponíveis na homepage do curso.

\section{REFERÊNCIAS}

ALFONSO-GOLDFARB, A. M.; FERRAZ, M. H. M.; BELTRAN, M. H. R. A historiografia contemporânea e as ciências da matéria: uma longa rota cheia de percalços. In: ALFONSO-GOLDFARB, A. M.; BELTRAN, M. H. R. (Org.) Escrevendo a História da Ciência: tendências, propostas e discussões historiográficas. São Paulo: Educ, 2004, p. 49 -72.

BARDIN, L. Análise de Conteúdo. Tradução de Luís Antero Reto, Augusto Pinheiro. São Paulo: Edições 70, 2016, 279 p.

BASTOS, F. O ensino de conteúdos de História e Filosofia da Ciência. Ciência \& Educação. v. 5, n. 1, p. 55-72, 1998.

BELTRAN, M. H. R.; SAITO, F.; TRINDADE, L. S. P. História da Ciência para formação de professores. São Paulo: Editora Livraria da Física, 2014, 128 p.

CAMPOS, D. F. A História da Ciência nas Licenciaturas em Ciências da Natureza no Instituto Federal de Goiás. 2016. 158 f. Dissertação (Mestrado em Ensino de Ciências e Matemática) - Universidade Estadual de Campinas, Campinas, 2016.

DELIZOICOV, N. C.; SLONGO, I. I. P.; HOFFMANN, M. B. História e Filosofia da Ciência e Formação de Professores: a proposição dos cursos de Licenciatura em Ciências Biológicas do Sul do Brasil. In: Congresso Nacional de Educação, 10., 2011, Curitiba. Atas X Congresso Nacional de Educação, Curitiba: PUCPR, 2011. Disponível em: <http://educere.bruc.com.br/CD2011/pdf/5568_3548.pdf > Acesso em: 26 fev. 2018. 
FERREIRA, A. M. P.; FERREIRA, M. E. M. P. A História da Ciência na formação de professores. História da Ciência e Ensino: construindo interfaces. v. 2, p. 1-13, 2010.

FLICK, U. Introdução à Pesquisa Qualitativa. 3 ed. Porto Alegre: Artmed, 2009. $405 \mathrm{p}$.

FORATO, T. C. M.; PIETROCOLA, M.; MARTINS, R. A. Historiografia e Natureza da Ciência na sala de aula. Caderno Brasileiro de Ensino de Física.v. 28, n.1, p. 2759, 2011.

GATTI, S. R. T. Análise de uma ação didática centrada na utilização da História da Ciência: uma contribuição para a formação inicial do docente de Física. 2005. 312f. Tese (Doutorado em Educação) - Universidade Estadual de Campinas, Faculdade de Educação, Campinas, 2005.

GATTI, S. R. T.; NARDI, R. (Org.). A História e a Filosofia da Ciência no Ensino de Ciências: a pesquisa e suas contribuições para a prática pedagógica. São Paulo: Escrituras, 2016. 240p.

GATTI, S. R. T.; NARDI, R. Considerações sobre as possibilidades de cooperação entre a universidade e as escolas: reflexões sobre a aproximação da História e Filosofia da Ciência na formação de professores de Física. In: Congresso Internacional sobre Investigação em Didática das Ciências, 9. 2013, Girona. Enseñanza de Las Ciencias - Número Extra. Barcelona. 2013. p.3526 - 3530.

GATTI, S. R. T.; NARDI, R.; SILVA, D. História da Ciência no Ensino de Física: um estudo sobre o ensino de atração gravitacional desenvolvido com futuros professores. Investigações em Ensino de Ciências.v.15, n.1, p. 7-59, 2010.

GIL-PÉREZ, D. Contribución de La Historia y de La Filosofía de las Ciencias al desarrollo de un modelo de enseñanza/aprendizaje como investigación. Enseñanza de Las Ciencias. v. 11, n.2, p.197-212, 1993.

GUARNIERI, P. V.; GATTI, S. R. T. A História e a Filosofia da Ciência no Ensino de Química: reflexões sobre a formação de professores a partir dos trabalhos apresentados nos ENPECs entre 2011 e 2015. In: Encontro Nacional de Pesquisa em Educação em Ciências, 11., 2017, Florianópolis. Atas do XI ENPEC, Florianópolis: ABRAPEC, 2017. Disponível em: $<$ http://www.abrapecnet.org.br/enpec/xienpec/anais/busca.htm?query=guarnieri> Acesso em: 05 dez. 2017. 
Science Educationis a Challenge: ananalysis of obstacles. Science \& Education, v. 20, p. 293-316, 2011.

LOMBARDI, O. I. La pertinencia de La Historia en La Enseñanza de Ciencias: argumentos y Contra argumentos. Enseñanza de Las Ciencias. v. 15, n.3, p. 343349, 1997.

LÜDKE, M.; ANDRÉ, M. Pesquisa em educação: abordagens qualitativas. São Paulo: EPU, 2012.

MARTINS, A. F. P. História e Filosofia da Ciência no Ensino: há muitas pedras nesse caminho. Caderno Brasileiro de Ensino de Física. v. 24, n. 1, p. 112-131, 2007.

MARTINS, R. A.; SILVA, C. C.; PRESTES, M. E. B. History and Philosophy of Science in Science Education, in Brazil. In: MATTHEWS, M. R. (ed.). International Handbook of Research in History, 317 Philosophy and Science Teaching. Springer, 2014, p. $2271-2299$.

MARTORANO, S. A. A. A transição progressiva dos modelos de ensino sobre cinética química a partir do desenvolvimento histórico do tema. 2012. $360 \mathrm{f}$. Tese (Doutorado em Ensino de Ciências) - Universidade de São Paulo, São Paulo, 2012.

MATTHEWS, M. R. História, Filosofia e Ensino de Ciências: a tendência atual de reaproximação. Caderno Catarinense de Ensino de Física, v. 12, n. 3, p. 164-214, 1995.

MORAIS, W. R. História e Natureza da Ciência no Ensino de Biologia: perfil e concepções de professores em serviço e de materiais didáticos. 2016. $230 \mathrm{f}$. Dissertação (Mestrado em Educação para a Ciência) - - Universidade Estadual Paulista "Júlio de Mesquita Filho", Bauru, 2016.

NORONHA, A. B. Interpretando a relatividade especial: discutindo o debate realismo e antirrealismo científicos no Ensino de Ciências. 2014. $381 \mathrm{f}$. Dissertação (Mestrado em Ensino de Ciências) - Universidade de São Paulo, São Paulo, 2014. meta-historiográfica. In: PEDUZZI, L. O. Q.; MARTINS, A. F. P.; FERREIRA, J. M. H. (Org.) Temas de História e Filosofia da Ciência no Ensino. Natal: EDUFRN, 2012, p. 41-64. 
PORTO, P. A. História e Filosofia da Ciência no Ensino de Química: Em busca dos objetivos educacionais da atualidade. Ensino de química em foco. Editora Unijuí, p.160-180, 2010.

QUEIRÓS, W. P. A articulação das culturas Humanística e Científica por meio do estudo Histórico-Sociocultural dos trabalhos de James Prescott Joule: contribuições para a formação de professores universitários em uma perspectiva transformadora. 2012. 355f. Tese (Doutorado em Educação para a Ciência) - Universidade Estadual Paulista “Júlio de Mesquita Filho", Bauru, 2012.

STANZANI, E. L.; GUARNIERI, P. V.; BASTOS, F. História da Ciência e Ensino de Química: potencialidades e obstáculos na construção de interfaces. In: Jornada de História da Ciência e Ensino, 5, 2015, São Paulo. Caderno de Resumos. São Paulo: Pontifícia Universidade Católica de São Paulo, 2015. p.28. Disponível em: <http://revistas.pucsp.br/index.php/hcensino/article/view/23541>. Acesso em: 23 nov. 2017.

TEODORO, S. R. A História da Ciência e as Concepções Alternativas de estudantes como subsídios para o planejamento de um curso sobre Atração Gravitacional. 2000. 280f. Dissertação (Mestrado em Educação para a Ciência) Universidade Estadual Paulista “Júlio de Mesquita Filho", Bauru, 2000. 
Recebido: 2018-04-07

Aprovado: 2018-06-02

DOI: 10.3895/rbect.v12n2.8134

Como citar: GUARNIERI, P. V.; GATTI, S. T. A relação entre o plano de ensino e a prática docente em uma disciplina específica de história e filosofia da ciência em um curso de licenciatura em química. Revista Brasileira de Ensino de Ciência e Tecnologia, v. 12, n. 2, 2019. Disponível em: <https://periodicos.utfpr.edu.br/rbect/article/view/8134>. Acesso em: xxx.

Correspondência: Patricia Vecchio Guarnieri - patyvecchio@gmail.com Direito autoral: Este artigo está licenciado sob os termos da Licença Creative Commons-Atribuição 4.0 Internacional. 